\title{
Cigarette Smoking Behavior and the Related Factors Among the Students of Mashhad University of Medical Sciences in Iran
}

\author{
Ehsan Taheri ${ }^{1}$; Ahmad Ghorbani ${ }^{2}$; Maryam Salehi ${ }^{3,4}$; Hamid Reza Sadeghnia ${ }^{1,2,5,}$ \\ ${ }_{1}^{1}$ Neurocognitive Research Center, School of Medicine, Mashhad University of Medical Sciences, Mashhad, IR Iran \\ ${ }_{2}^{2}$ Pharmacological Research Center of Medicinal Plants, School of Medicine, Mashhad University of Medical Sciences, Mashhad, IR Iran \\ 3 Department of Community Medicine, School of Medicine, Mashhad University of Medical Sciences, Mashhad, IR Iran \\ ${ }_{4}^{4}$ Repartmen Center for Patient Safety, School of Medicine, Mashhad University of Medical Sciences, Mashhad, IR Iran \\ ${ }_{5}^{4}$ Research Center for Patient Safety, School of Medicine, Mashhad University of Medical Sciences, Mashhad, IR Iran \\ *Corresponding Author: Hamid Reza Sadeghnia, Pharmacological Research Center of Medicinal Plants, Mashhad University of Medical Sciences, Mashhad, IR Iran. Tel:+98-5138828566, \\ Fax:+98-5138828567, E-mail: sadeghniahr@mums.ac.ir
}

Received: December 10, 2013; Revised: June 24, 2014; Accepted: September 28, 2014

\begin{abstract}
Background: Tobacco consumption is the second major cause of death and the fourth most common risk factor for diseases, worldwide. Epidemiologic studies have traced the use of alcohol, tobacco, and illicit substances among medical students and physicians.

Objectives: The current study aimed to investigate the prevalence of cigarette smoking and the related factors among the students of medical sciences in Mashhad University of Medical Sciences, Mashhad, Iran.

Patients and Methods: This cross-sectional study was conducted on 946 health professional students in Mashhad University of Medical Sciences (MUMS, Iran) in autumn 2008. A standard self-administered questionnaire consisting of socio-demographic data, participant smoking status, family and peer smoking, attitudes and beliefs about smoking, awareness of cigarette negative effects and reasons for smoking cessation was used in the current study.

Results: Among the students, $18.3 \%$ reported having ever tried or experienced with cigarette smoking. The overall prevalence of cigarette smoking was $9.8 \%$ with significant differences in prevalence rates by gender, $17.6 \%$ among males and $4.2 \%$ among females. Starting and continuing smoking was significantly correlated with the family cigarette consumption habits. The most common reason to start smoking was friends (24.9\%) and the most important reason to continue smoking was personal life distress (17.6\%). The majority of participants (92.3\%) reported that they were aware of the hazards of smoking. A significant difference regarding awareness of smoking hazards was observed between smokers and non-smokers. The most important preventive factor for cigarette smoking was religious beliefs (69.1\%). Conclusions: Although the prevalence of regular smokers among health professions students of MUMS was lower than general populations, but this level is still alarming and points at the rapid growth of cigarette use, especially among female students. Medical schools should work harder to tackle this phenomenon and address it more efficiently in their curricula.
\end{abstract}

Keywords:Cigarette; Health; Smoking; Students

\section{Background}

According to the World Health Organization reports (WHO), 22\% of the world's population aged over 15 years are smokers and approximately six million people die from tobacco use or exposure to tobacco smoke. Studies in Iran show that about $26 \%$ of the Iranian men and $3.6 \%$ of the women participating in the study are current smokers (1). Unfortunately, the prevalence of smoking between college students is higher than in the general population in Iran. With a cross-sectional population-based study, Fotouhi et al. reported that prevalence of smoking in residents of Tehran, capital of Iran, is 12\% (2). On the other hand, Jafari et al. found that among the students of Tehran University, $35.4 \%$ of men and $12.6 \%$ of women are smokers (3). The high prevalence of smoking (42.5\%) among university students was also reported by other investigators in the Middle-East countries (4).

Cigarette use among medical students is of particu- lar concern because medically educated persons play a leading role in the development of overall public health policy and the prevention of tobacco use in the society. In some studies on medical students in the developed countries, the smoking rate was 16-21\% (5-8). On the other hand, a multi-country survey in the developing countries revealed a smoking prevalence rate of $11 \%, 6.7 \%, 10.6 \%, 17.8 \%$ and $17.4 \%$ among medical students of Malaysia, India, Pakistan, Nepal and Bangladesh, respectively (9). Although many researches are conducted in different countries, there have been few researches on cigarette smoking in Iran. Nazary et al. studied the prevalence of smoking among male students in Semnan University of Medical Sciences, Iran, and found a smoking rate of $14.4 \%$ (10). In another study, Ahmadi et al. assessed the prevalence of cigarette smoking among students of Shiraz University of Medical Sciences. The authors reported that $16.79 \%$ of

Copyright ( 2015, Iranian Red Crescent Medical Journal. This is an open-access article distributed under the terms of the Creative Commons Attribution-NonCommercial 4.0 International License (http://creativecommons.org/licenses/by-nc/4.0/) which permits copy and redistribute the material just in noncommercial usages, provided the original work is properly cited. 
males and $0.69 \%$ of females were smokers. The internship students showed the highest prevalence of smoking (17\%) among the medical students (11). The preliminary studies highlight the need for performing more investigations on the prevalence and determinants of tobacco use and developing effective cessation interventions for health professional students.

\section{Objectives}

The current study aimed to investigate the prevalence of active cigarette smoking, socio-demographic data, knowledge and attitudes about cigarette use, exposure to second-hand tobacco smoke, attitude of willingness to stop smoking, etc. among health professional students in MUMS, Mashhad, Iran.

\section{Patients and Methods}

The current cross-sectional study was conducted on the students of six faculties of MUMS (dentistry, medicine, midwifery and nursing, pharmacy, paramedical sciences and public health) in autumn (October and November) 2008. A standard self-administered questionnaire adopted from the Global Health Professional Survey (GHPS), designed for health professionals by the WHO and the Canadian Public Health Association was used in this study (12). The questionnaires were distributed to all 1100 students residing in dormitories of MUMS. The inclusion criteria for the analysis were (a) student status, (b) age between 18 and 28 years, (c) consent to participate in the survey, and (d) no missing data for the tobacco-related variables. A total of 936 students met these criteria and completed the information (about 85\%). Informed consent was obtained from each participant included in the study and the study protocol conformed to the ethical guidelines of the 1975 Helsinki Declaration. Ethical approval was granted by MUMS Ethics Committee prior to the data collection (ethical approval code: 87685 ). The study proposal and instruments were approved by the MUMS research committee. Before distributing the questionnaires, the students were informed that the information collected would be kept anonymous and that participation was completely voluntary.

The questionnaire was designed in three parts; the first part consisted of socio-demographic data (age, sex, health professional discipline, marital status and ethnicity), smoking status of their father/mother/other family members, daily exposure to cigarette smoking and participant smoking status (current smokers including daily smokers and occasional smokers and former smokers). The second part of the questionnaire included the data on attitudes towards using or not using cigarettes, age of the smoking onset, reasons to start smoking, reasons to continue smoking, number of cigarettes smoked per day, duration of smoking, places most commonly smoked in, and the number of quit attempts. The third part included the questions regarding the cigarette advertisements and prohibitions, awareness of cigarette negative effects and reasons, smoking cessation, and the reaction of participant in places where there are people who smoke.

In accordance with the WHO guidelines, the students were categorized as daily smokers, occasional smokers, former smokers or nonsmokers. Daily smokers were defined as those who smoked at least one cigarette per day for at least one month before completing the questionnaire; occasional smokers were defined as those who did not smoke daily; former smokers (ex-smokers) were defined as those who previously had a daily smoking habit for a continuous period of six months but had given up smoking at least one month prior to completion of the questionnaire; and nonsmokers were defined as those who had never smoked or who had been smoking for less than one month. No missing values were reported by the investigators. Descriptive data analysis was performed using Statistical Package for the Social Sciences (SPSS) version 17.0. The Chi-square test was used for statistical analysis. The significance level was set at $\mathrm{P}<0.05$. To assess the independent effect of individual factors, multiple logistic regression analysis was used and odds ratio (OR) with 95\% CIs were computed.

\section{Results}

Among all 936 students included in the study, 44.6\% were male and $55.4 \%$ were female (Table 1 ). The effects of various independent variables on the prevalence rate of cigarette smoking were investigated, and odds ratios were calculated. The overall prevalence of cigarette smoking was $9.8 \%$ with significant differences in prevalence by gender; $17.6 \%$ among males and $4.2 \%$ among females $\left(\chi^{2}\right.$ $70.57 ; \mathrm{P}<0.001)$. Prevalence of smoking did not significantly change according to the year of study: first year, $7 \%$; second year, $8 \%$; third year,8.3\%; fourth year, $17 \%$; fifth year, 11\%; sixth year, $20 \%$; seventh and over, $6.7 \%\left(\chi^{2} 3.49\right.$; P $>0.05$ ). Also, the mean age of starting cigarette was 19.6 \pm 2.5 and $18.9 \pm 2.4$ years for male and female students, respectively.

Among all students, 18.3\% (95\% CI 8.2-15.4) reported never having tried or experienced cigarette smoking. The prevalence of daily, occasional and former smokers was $9.8 \%, 3 \%$ and $5 \%$, respectively (Table 2). Also, analysis of data showed that men were significantly more likely to become daily smokers than women (18.9\% vs. $2.5 \%$; P $\left.<0.001 ; \chi^{2} 70.57\right)$. The onset age of female students who smoked regularly was $18.9 \pm 2.4$ years, lower but not statistically significant compared to that of male students (19.6 \pm 2.56 years). Most of the men (26.6\%) and women (44.5\%) were smokers for more than four years (Table 3 ). Also, it was found that $50 \%$ of the students had smokers in their family, father, mother, brother or sister (Table 4).

Table 5 summarizes the reasons of students' attitudes toward starting and continuing smoking. The most common reasons to start smoking were ranked as follows: friends (24.9\%), distress and anxiety due to dormitory residency $(23 \%)$ or pleasure and fun (22.8\%). On the other 
hands, the most important reasons to continue smoking was personal life distress (17.6\%). Most of the smokers (53\%) reported that they achieved their goals set prior to the onset of smoking and $18.5 \%$ of smokers believed that cigarette smoking was not helpful to achieve their goals, while $28.4 \%$ had no knowledge about it. The number of cigarettes per day was 1-5, 6-10, 11-15, and 16-20 cigarettes in $25 \%, 32 \%, 17.7 \%$ and $25.5 \%$ of smokers, respectively. Favorite smoking places were as follows: parks and campus (37.8\%), dormitory (18\%), no particular places (9.4\%), at parties (8\%) and bath room (7.1\%).

The majority of participants (92.3\%) reported that they were aware of the hazards of smoking. A significant difference regarding awareness of smoking hazards was observed between smokers and non-smokers $\left(\chi^{2} 604.17\right.$; P $<0.001)$. Significant gender differences $\left(\chi^{2} 11.11, \mathrm{P}<0.001\right)$ were also found in smoking hazards beliefs. Females (97.9\%) were more likely to agree with smoking hazard effects on health than males (85.5\%). In the current study, $5 \%$ of the participants reported that they have a history of successfully quitting cigarette smoking. They believed that the nisus (50\%) was the most important reason to quit smoking. Better knowledge about dangerous effects of cigarette smoking on health $(27.8 \%)$ and caring for one's own health (11\%) were the most important reasons to quit smoking. Among the smokers, 90\% intended to quit smoking, $45.4 \%$ had tried to quit smoking without any success, and $54.6 \%$ believed themselves able to quit smoking.

All of the nonsmokers stated that they avoided environments where people were smoking, because of complications like respiratory distress (60.6\%), hatred toward smoking persons (55.8\%), headache (42.5\%) and other problems such as nausea and vomiting, coughing and tearing. The most important preventive factors upon cigarette smoking were as follows: religious beliefs (70\%), parents (40.2\%), knowledge about cigaretteinduced health problems (33.4\%), information from mass media about the hazards of smoking (19\%), and close friends (18.7\%).

Table 1. Demographic Characteristics and Odds Ratio of Factors Associated With Smoking Status Among Students of Mashhad University of Medical Sciences a, b

\begin{tabular}{|c|c|c|c|c|c|}
\hline Features & Participants & Smoker & Odds Ratio & CI & P Value \\
\hline Age, $y$ & & & & & $<0.001$ \\
\hline $18-21$ & $547(58.3)$ & $39(7.2)$ & & & \\
\hline $22-25$ & $335(35.9)$ & $48(14.3)$ & 2.161 & $1.383-3.378$ & \\
\hline$\geq 26$ & $54(5.8)$ & $5(9.3)$ & 1.319 & $0.497-3.500$ & 0.579 \\
\hline Gender & & & & & $<0.0001$ \\
\hline Female & $519(55.4)$ & $13(14.1)$ & & & \\
\hline Male & $417(44.6)$ & $79(85.9)$ & 9.097 & $4.980-16.619$ & \\
\hline Marital status & & & & & $<0.0001$ \\
\hline Married & $159(9)$ & $15(9.4)$ & & & \\
\hline Single & $777(83)$ & $77(9.9)$ & 1.087 & $0.528-2.238$ & \\
\hline \multicolumn{6}{|l|}{ Ethnicity } \\
\hline Fars & $734(78.4)$ & $51(6.9)$ & & & \\
\hline Turk & $54(5.8)$ & $13(24.1)$ & 4.246 & $2.139-8.429$ & $<0.0001$ \\
\hline Kurd & $41(4.4)$ & $3(7.3)$ & 1.057 & $0.315-3.543$ & 0.928 \\
\hline Lor & $33(3.5)$ & $15(45.5)$ & 11.160 & $5.314-23.436$ & $<0.0001$ \\
\hline Others & $74(7.9)$ & $10(13.5)$ & 2.101 & $0.946-4.665$ & 0.068 \\
\hline
\end{tabular}

Abbreviation: $\mathrm{CI}$ confidence interval.

b Data are presented as No.(\%).

Table 2. Gender-Related Smoking Status in Students of Mashhad University of Medical Sciences a

\begin{tabular}{|c|c|c|c|c|c|}
\hline Variable & Daily & Occasional & Former Smokers & Nonsmokers & Total \\
\hline \multicolumn{6}{|l|}{ Gender } \\
\hline Male & $79(18.9)$ & $31(7.5)$ & $32(7.7)$ & 275 (65.9) & $417(100)$ \\
\hline Female & $13(2.5)$ & - & $16(3.1)$ & $490(94.4)$ & $519(100)$ \\
\hline Total & $92(9.8)$ & $31(3.4)$ & $48(5.1)$ & $765(81.7)$ & $936(100)$ \\
\hline
\end{tabular}

a Data are presented as No.(\%). 
Taheri E et al.

\begin{tabular}{|c|c|c|c|}
\hline Variable & Male & Female & Total \\
\hline \multicolumn{4}{|l|}{ Duration } \\
\hline$<6$ Months & 25 & 11.1 & 23.3 \\
\hline 6 Months-1 year & 26.6 & 22.2 & 26 \\
\hline 2 Years & 18.8 & 11.1 & 17.8 \\
\hline 3 Years & 1.6 & 11.1 & 2.7 \\
\hline$>4$ Years & 26.6 & 44.5 & 28.8 \\
\hline
\end{tabular}

\begin{tabular}{lccc}
\hline Table 4. Familial Smoking Status and Predicting Current Smoking Among Students of Mashhad University of Medical Sciences \\
\hline Variable & Prevalence, $\%$ & Odds Ratio & P Value \\
\hline No family's smoking & 50 & & $<0.001$ \\
Father's smoking & 37 & 4.752 & $<0.001$ \\
\hline $\begin{array}{l}\text { Mother's smoking } \\
\text { Brother's or sister's smoking }\end{array}$ & 23 & 20.95 & $<0.001$ \\
$\begin{array}{l}\text { More than one smoker in } \\
\text { family }\end{array}$ & 16.3 & 4.422 & $<0.001$ \\
\hline
\end{tabular}

\begin{tabular}{lcc}
\hline Table 5. The Most Common Reasons to Start and Continue Smoking in Students of Mash had University of Medical Sciences a \\
\hline Reasons & Starting Smoking & Continuing Smoking \\
\hline Friend & 24.9 & 13.2 \\
Distress and anxiety due to dormitory residency & 23 & 10.3 \\
Pleasure and fun & 22.8 & 11.8 \\
Relaxation & 8.3 & 7.4 \\
Personal life problems & 7.2 & 17.6 \\
Other reasons & 13.8 & 39.7 \\
Total & 100 & 100 \\
\hline
\end{tabular}

a Data are presented as \%.

\section{Discussion}

The collected data showed that cigarette smoking was common (10\%) among medical students in Mashhad. Previous studies in other cities of Iran revealed that prevalence of smoking was $9 \%, 6 \%, 11 \%$ and $7.4 \%$ in Shiraz, Golestan, Kerman and Ardabil Universities of Medical Sciences, respectively (13-16). Therefore, it seems that the prevalence of smoking among Iranian health professional students is approximately in the range of $6 \%$ to $11 \%$. Regarding the other countries in the Middle-East, approximately similar prevalence (11\%) was found by Almerie et al. among the medical students of Syria (17). On the other hand, other researchers reported different incidence of smoking among medical students in the United State (20\%), Germany (25\%), Turkey (22\%), Brazil (16.5\%), Jordan (28.6) and Hong Kong (0.7\%) (5-8, 18, 19). Therefore, the prevalence of tobacco smoking in the current sample is still lower than those of medical students in many other countries. Also, a cross-country, cross-sec- tional study among 12 medical schools in four countries in Europe (Germany, Italy, Poland and Spain) found that the overall prevalence of smoking among medical students (almost 30\%) was higher than the general population (20). On the other hand, the rate of regular smokers in the MUMS is relatively smaller than that of general population in Mashhad city (12.7\%) described by Boskabady et al. (21). According to the current study data, the prevalence of smokers in male students was more than females. Besides, the study found that in Mashhad city, the prevalence of female smokers in students of medical sciences was $17.6 \%$ which is markedly higher than that of general population (1.7\%) reported by Boskabady et al.(21). Therefore, this point emphasized the necessity for a quit-smoking plan and a more active approach to prevent smoking among female medical students. Moreover, the average age of starting smoking in the current sample was almost 19 years, which is two years lower 
Taheri E et al.

than that of general population in Mashhad and Shiraz cities, Iran $(1,22)$. The smoking onset age indicates that most of the participants started smoking after attending the university.

In the current study, the most common reason to start smoking was friends. In agreement with the current study findings, previous studies on medical students in Japan and Albania also reported that friends were the most important factor associated with smoking behavior $(22,23)$. Also in the current study student sample about $50 \%$ of the participants had smokers in their family, which again emphasizes on the important role of relatives and friends on starting cigarette smoking. More prevalence of smoking in some ethnicities, particularly Turk and Lor, emphasizes on identifying the ethnicity and cultural factors which influence the smoking behavior and probably manifests the lower knowledge of these groups regarding smoking complications. Sixth-year students had higher prevalence of smoking (20\%) than the students in the other study years. Therefore, it seems that the students in the last years of education need a specific training regarding smoking cessation.

Understanding the prevalence and the factors associated with cigarette use among the health professional students is of particular concern because medically educated persons play a leading role in the development of overall public health policy and prevention of tobacco use in the society. Thus, this understanding will aid to design tobacco/substance abuse prevention and control activities in the populations. The present study had also some limitations. Regarding sampling, in order to include as many students as possible, the questionnaires were distributed to the students in dormitories. Living without parents (in dormitories) is accompanied with freedom of previous limitations which can be associated with some changes in individual's life (3). Therefore, the prevalence of smoking among the students living in dormitories may not be exactly the same as the general population of MUMS students. Also, under-reporting of smoking was possible, because health professional students may be more sensitized than the other populations to reporting their smoking habits $(18,24)$. In addition, the study used a cross-sectional design to collect data on smoking behavior and related factors and possible bias could have occurred. Smoking among medical students and health professionals is a serious concern because they should play important roles in smoking prevention and in assisting patients to quit smoking. This indicated the necessity of much more attention to educate the health professional students.

In conclusion, although the prevalence of regular smokers among health professions students of MUMS was lower than those of the general populations, this level was still alarming and pointed at the rapid growth towards cigarette use, especially among female students. Medical schools should work harder to tackle this phenomenon and address it more efficiently in their curricula.

\section{Acknowledgements}

Authors wish to thank Miss Maryam Masumi for her valuable contribution.

\section{Authors' Contributions}

Hamid Reza Sadeghnia and Ehsan Taheri designed the study, collected data and wrote the first draft of the manuscript. Ahmad Ghorbani and Maryam Salehi performed the statistical analysis, managed the literature searches and reviewed the manuscript. All authors read and approved the final version of the manuscript.

\section{Funding/Support}

This work was supported by Mashhad University of Medical Sciences, Iran.

\section{References}

1. Ahmadi J, Khalili H, Jooybar R, Namazi N, Mohammadagaei P. Prevalence of cigarette smoking in Iran. Psychol Rep. 2001;89(2):339-41.

2. Fotouhi A, Khabazkhoob M, Hashemi H, Mohammad K. The prevalence of cigarette smoking in residents of Tehran. Arch Iran Med. 2009;12(4):358-64.

3. Jafari F, Haji Zamani A, Alizadeh K. Reviewing the prevalence of (cigarette) smoking and its related factors in students of tehran university, iran. Addict Health. 2011;3(3-4):105-10.

4. Metintas S, Sariboyaci MA, Nuhoglu S, Metintas M, Kalyoncu C, Etiz S, et al. Smoking patterns of university students in Eskisehir, Turkey. Public Health.1998;112(4):261-4.

5. Kusma B, Quarcoo D, Vitzthum K, Welte T, Mache S, Meyer-Falcke A, et al. Berlin's medical students' smoking habits, knowledge about smoking and attitudes toward smoking cessation counseling. J Occup Med Toxicol. 2010;5:9.

6. Senol Y, Donmez L, Turkay M, Aktekin M. The incidence of smoking and risk factors for smoking initiation in medical faculty students: cohort study. BMC Public Health. 2006;6:128.

7. Stramari LM, Kurtz M, Silva LC. Prevalence of and variables related to smoking among medical students at a university in the city of Passo Fundo, Brazil.J Bras Pneumol. 2009;35(5):442-8.

8. Warren CW, Sinha DN, Lee J, Lea V, Jones NR. Tobacco use, exposure to secondhand smoke, and cessation counseling among medical students: cross-country data from the Global Health Professions Student Survey (GHPSS), 2005-2008. BMC Public Health. 2011;11:72.

9. Sreeramareddy CT, Suri S, Menezes RG, Kumar HN, Rahman M, Islam MR, et al. Self-reported tobacco smoking practices among medical students and their perceptions towards training about tobacco smoking in medical curricula: A cross-sectional, questionnaire survey in Malaysia, India, Pakistan, Nepal, and Bangladesh. Subst Abuse Treat Prev Policy. 2010;5:29.

10. Nazary AA, Ahmadi F, Vaismoradi M, Kaviani K, Arezomandi M, Faghihzadeh S. Smoking among male medical sciences students in Semnan, Islamic Republic of Iran. East Mediterr Health J. 2010;16(2):156-61.

11. Ahmadi J, Khalili H, Jooybar R, Namazi N, Aghaei PM. Cigarette smoking among Iranian medical students, resident physicians and attending physicians. Eur J Med Res. 2001;6(9):406-8.

12. Gtss Collaborative Group... Tobacco use and cessation counselling: Global Health Professionals Survey Pilot Study, 10 countries, 2005. Tob Control. 2006;15 Suppl 2:ii31-4.

13. Afrasiabifar A, Derakhshan A, Sadeghi Hasanabadi A, Rajaeifard AAR. A survey of cigarette smoking tendency and its associated causes among students of Shiraz University of Medical Sciences, 1998. Armaghan Danesh. 2001;19:42-8.

14. Majidpour A, Hamidzadeh Arbaby Y, Abbasgholizadeh N, Salehy S. Prevalence and causes of tendency to cigarette smoking 
among students in Ardabil University of Medical Sciences. J Ardabil Univ Med Sci. 2005;3:266-70.

15. Nakhaee N, Divsalar K, Bahreinifar S. Prevalence of and factors associated with cigarette smoking among university students: a study from Iran. Asia Pac J Public Health. 2011;23(2):151-6.

16. Shojaa M, Jouybari L, Qorbani M, Sanagoo A, Shojaee H, Kia Kajoori Z, et al. Prevalence and cause of smoking among the dormitories students in Gorgan University of Medical Sciences. Pajouhandeh . 2010;15(3):123-8.

17. Almerie MQ, Matar HE, Salam M, Morad A, Abdulaal M, Koudsi A, et al. Cigarettes and waterpipe smoking among medical students in Syria: a cross-sectional study. Int J Tuberc Lung Dis. 2008;12(9):1085-91.

18. Lam TS, Tse LA, Yu IT, Griffiths S. Prevalence of smoking and environmental tobacco smoke exposure, and attitudes and beliefs towards tobacco control among Hong Kong medical students. Public Health. 2009;123(1):42-6.

19. Haddad LG, Malak MZ. Smoking habits and attitudes towards smoking among university students in Jordan. Int J Nurs Stud.
2002;39(8):793-802.

20. La Torre G, Kirch W, Bes-Rastrollo M, Ramos RM, Czaplicki M, Gualano MR, et al. Tobacco use among medical students in $\mathrm{Eu}-$ rope: results of a multicentre study using the Global Health Professions Student Survey. Public Health. 2012;126(2):159-64.

21. Boskabady MH, Mahmoudinia M, Eslamizade MJ, Boskabady M, Shakeri MT, Heydari GR. The prevalence of smoking among the population in the city of Mashhad (north east of Iran) and pulmonary function tests among smokers. Pneumonol Alergol Pol. 2011;79(1):21-5.

22. Ohida T, Kamal AA, Takemura S, Sone T, Minowa M, Nozaki S. Smoking behavior and related factors among Japanese nursing students: a cohort study. Prev Med. 2001;32(4):341-7.

23. Vakeflliu Y, Argjiri D, Peposhi I, Agron S, Melani AS. Tobacco smoking habits, beliefs, and attitudes among medical students in Tirana, Albania. Prev Med. 2002;34(3):370-3.

24. Xiang H, Wang Z, Stallones L, Yu S, Gimbel HW, Yang P. Cigarette smoking among medical college students in Wuhan, People's Republic of China. Prev Med.1999;29(3):210-5. 